\title{
Clinical features, anger management and anxiety: a possible correlation in migraine children
}

\author{
Samuela Tarantino ${ }^{1}$, Cristiana De Ranieri ${ }^{2}$, Cecilia Dionisi ${ }^{3}$, Monica Citti ${ }^{1}$, Alessandro Capuano ${ }^{1}$, Federica Galli ${ }^{4}$, \\ Vincenzo Guidetti ${ }^{3}$, Federico Vigevano ${ }^{1}$, Simonetta Gentile ${ }^{2}$, Fabio Presaghi ${ }^{3}$ and Massimiliano Valeriani ${ }^{1,5^{*}}$
}

\begin{abstract}
Background: Psychological factors can increase severity and intensity of headaches. While great attention has been placed on the presence of anxiety and/or depression as a correlate to a high frequency of migraine attacks, very few studies have analyzed the management of frustration in children with headache. Aim of this study was to analyze the possible correlation between pediatric migraine severity (frequency and intensity of attacks) and the psychological profile, with particular attention to the anger management style.
\end{abstract}

Methods: We studied 62 migraineurs (mean age 11.2 2.1 years; $29 \mathrm{M}$ and $33 \mathrm{~F}$ ). Patients were divided into four groups according to the attack frequency (low, intermediate, high frequency, and chronic migraine). Pain intensity was rated on a 3-levels graduate scale (mild, moderate and severe pain). Psychological profile was assessed by Picture Frustration Study test for anger management and SAFA-A scale for anxiety.

Results: We found a relationship between IA/OD index (tendency to inhibit anger expression) and both attack frequency $(r=0.328, p=0.041)$ and intensity $(r=0.413, p=0.010)$. When we analyzed the relationship between anxiety and the headache features, a negative and significant correlation emerged between separation anxiety (SAFA-A Se) and the frequency of attacks $(r=-0.409, p=0.006)$. In our patients, the tendency to express and emphasize the presence of the frustrating obstacle (EA/OD index) showed a positive correlation with anxiety level ("Total anxiety" scale: $r=0.345 ; p=0.033$ ).

Conclusions: Our results suggest that children suffering from severe migraine tend to inhibit their angry feelings. On the contrary, children with low migraine attack frequency express their anger and suffer from separation anxiety.

Keywords: Migraine, Anger, Anxiety, Children

\section{Background}

The role of affective factors in the experience of pain has received a great deal of attention over the past few decades. While several studies investigated the relationship between depression, anxiety and headache in both adult [1-3] and paediatric age [3,4], only a few reports dealt with anger.

Studies on chronic pain syndromes suggested that the way of expression/management of anger has an important effect on disease course and impact [5-7]. In particular, failure to express one's own anger is related to more intense and frequent pain $[5,6,8]$. On the other hand,

\footnotetext{
* Correspondence: m.valeriani@tiscali.it

'Division of Neurology, Headache Centre, Ospedale Pediatrico Bambino Gesú, IRCCS, Rome, Italy

${ }^{5}$ Center for Sensory-Motor Interaction, Aalborg University, Aalborg, Denmark Full list of author information is available at the end of the article
}

patients with chronic pain conditions show a significantly greater tendency, as compared to healthy subjects, to inhibit anger $[5,9,10]$. It is possible that the experience of long-lasting persistent pain leads to anger inhibition. Thus, a vicious circle can be established in which anger is inhibited by chronic pain and retained anger can increase affective component of pain.

That the relationship between anger and headache has been only rarely explored could be due to the complexity of defining anger and related constructs. Level of emotional intensity and physiological arousal related to anger show a large inter- and intra-individual variability [11]. Not only the frequency of anger expression, but also the way one's own anger appears can be extremely variable. Anger expression refers to the usual models of expressing anger feeling. Three different components 
may be considered: 1) internalised anger, 2) externalised anger, and 3) anger control. Internalised anger (anger-in) reflects the tendency to suppress angry feeling. It occurs when an individual does not express his own anger outwardly, but inwardly, thus feeling considerable internal stress. In contrast, externalised anger (anger-out) leads to aggressive behaviour, such as physical or verbal acts against objects or persons in the environment. Lastly, anger-control refers to the ability to monitor and prevent the experience of anger [11].

Adults suffering from headache typically have a significant impartment in their ability to control and express angry feelings, as compared to healthy subjects [12-16]. Possible relationship between anger expression and severity of headache (frequency and intensity of the attacks) are scarce [13,15-17].

In children, data investigating a possible link between anger and headache are even fewer. To the best of our knowledge, only three studies described the role of anger in children suffering from headache and they did not use specific or standardized tools to assess the anger management style [18-20]. Moreover, in only one study [19] the ICHD-II diagnostic criteria [21] were considered.

It has been reported that migraine patients experience anxiety and/or guilt after expressing anger feeling [22]. However, the relationship between anxiety and anger has rarely been investigated in headache patients and no study was conducted in a pediatric population $[12,16]$.

In the present study, we aimed to investigate the possible relationship between anger management and migraine severity (frequency and intensity of attacks) in a selected population of migrainous children/adolescents. Moreover, anxiety was also investigated in both its effect on frequency and severity of headache and its relationship with anger. We hypothesized that: 1) patients who fail to externalize their anger have higher headache frequency and intensity, 2) patients with higher anxiety scores suffer from more frequent and severe headache attacks, 3) anger expression shows a positive correlation with anxiety scores.

\section{Methods}

\section{Subjects and procedures}

We enrolled sixty-two $(N=62)$ consecutive patients suffering from migraine without aura (MoA, ICHD-II) [21] (age range $8-16$ years; mean age $11.2 \pm 2.1$ years). They were consecutively chosen from patients referred for consultation to our Headache Centre. Twenty-nine were male (46.8\%) and thirty-three were female (53.2\%). MoA was diagnosed according to the criteria of the International Classification of Headache Disorders, 2nd edition (ICHD-II) [21].

At the initial visit, all patients were given a headache diary where they had to sign the main features of their headache. Data on the clinical characteristics of headache, including frequency and intensity of the attacks, were issued from the diary that was brought back at the second consultation. The attack frequency of patients suffering from episodic migraine was divided in high (HF; $10-14$ attacks a month), intermediate (IF; from 5 to 9 attacks per month) and low frequency (LF; from less than once a month to 4 attacks per month). Patients who suffered from $\geq 15$ attacks per month were included under the category of chronic migraine (CM). Our patients were asked to rate pain intensity on a 3-levels graduate scale: 1 ) mild pain (MP), allowing the subject to continue his daily activities; 2 ) moderate pain (MoP), leading to interruption of patient' activities; and 3) severe pain (SP), forcing the child to go to bed.

None of the patients were receiving medications and none of them had been treated with drugs acting on the central nervous system, including drugs for migraine prophylaxis. We ensured that they did not suffer from any other neurological or internal disease.

Psychological evaluation was performed in a single session by the same examiner (S.T.) with a specific training on the psychological assessment of children and adolescents. In order to exclude a possible direct effect of pain on psychological assessment, we ensured us that no patient had a headache attack within $24 \mathrm{~h}$ before the psychological study.

All the patients were able to understand and to complete the tasks. None of them had ever had a previous psychological screening.

All participants and their parents gave signed, informed consent to participate to the study. The study was approved by the local ethics committee and was conducted in compliance with the Helsinki Declaration.

\section{Psychological tools}

Psychological tools employed in our study were:

- The Italian translation of the Rosenzweig Picture Frustration Study (PFS) for the anger management style [23]. It is a projective procedure to identify the patterns of response to daily stress/frustration and takes about 10-20 min to be completed. Subjects were seated in a shining and quiet room and were given a booklet including 24 black and white cartoon scenarios. These scenarios present different frustrating social situations. Each picture contains one person (P1) saying something to another person (P2) who has a blank speech box next to him/her. The patient was instructed to imagine what the P2 subject would say and to write this response in the blank speech box. Migraineurs were asked to complete the task as quickly as possible. In the present study, PFS for children (4-12 years) and for 
adolescents (13-18 years) were used. Both of them analyze how patients react to frustration in different situations (school, family and social) and they differ mainly in the age of the persons represented in the cartoons. Each subject's answers to all 24 items is subsequently categorized according to nine dimensions obtained by the combination of three possible directions and of three types of aggression. Aggression may be directed: 1) toward the environment (E-extraggression), 2) toward oneself (I-intraggression), or 3) evaded (M-imaggression). There are 3 types of aggression, divided on the base of where subject's attention is addressed: 1 ) focus on objects (OD-obstacle-dominance), 2) focus on people (ED-ego-defence), and 3) focus on the problem solution (NP-need-persistence). The number of times each of the 24 items is classified within the nine dimensions of anger management is the score used in the present study (Table 1). The PSF showed an inter-rater reliability ranging from $79 \%$ to $85 \%$ and demonstrates satisfactory testretest reliability [24].

- The Italian SAFA battery of tests (Psychiatric scales for self-administration for youths and adolescents) [25]. It allows examiners to explore a wide series of symptoms and psychological conditions. The entire battery includes a total of six scales (each with subscales) that can also be used separately. It evaluates anxiety-related areas (SAFA A), depression-related areas (SAFA D), obsessivecompulsive symptoms (SAFA O), somatic concerns (SAFA S), psychogenic eating disorders (SAFA P) and phobias (SAFA F). The administration can be either individual or collective (for example, screening in schools) and lasts between 30 and 60 minutes. The SAFA battery is organized to fit the mode of understanding and evaluation of a large age group: each questionnaire is in fact composed of a version for children aged 8 to 10 years (identified with the letter " $\mathrm{e}$ ") and a version only for subjects from 11 to 18 years (identified with the letters "ms"). Only the scale for anxiety presents three distinct versions: 8-10 years ("e"), 11-13 years ("m") and 14-18 years ("s"). There are three possible responses to each item: 'true, false and partly true'; the sum of points achieved in each scale and subscale can be converted into $T$ scores, sten points and percentiles. On the basis of the obtained scores, it is possible to build a general profile and/or individual profiles within the single scales. The scales showed good internal consistency (Cronbach alpha $>0.80$ ) and test-retest stability. According to the aim of our study, we administered the scale for assessment of anxiety (SAFA-A). It includes several subscales ("Generalized anxiety", "Social anxiety", "Separation anxiety", "School anxiety") and produces a "Total anxiety" score.

\section{Statistical analysis}

Statistical evaluation was performed using Statistical Package for the Social Sciences (SPSS 18.0) software.

According to the aim of our study, we grouped the patients based on attack frequency (LF, IF, HF and $\mathrm{CH}$ groups) and pain severity (MP, MoP, and SP groups).

Table 1 PFS dimensions

\begin{tabular}{|c|c|c|c|}
\hline \multirow{3}{*}{$\begin{array}{l}\text { Direction } \\
\text { of aggression }\end{array}$} & \multicolumn{3}{|c|}{ Type of aggression } \\
\hline & Obstacle dominance (OD) & Ego-defence (ED) & Needs- persistence (NP) \\
\hline & (The obstacle is prominent) & The people are prominent & The solution is prominent \\
\hline $\begin{array}{l}\text { Extra- } \\
\text { aggression (EA) }\end{array}$ & $\begin{array}{l}\mathrm{E}^{\prime} \text { - The presence of the obstacle } \\
\text { frustrating is emphasized insistently. }\end{array}$ & $\begin{array}{l}\text { E - Blame and hostility are directed } \\
\text { toward a person or object in the } \\
\text { environment. }\end{array}$ & $\begin{array}{l}\mathrm{E} \text { - A solution to the frustrating situation is } \\
\text { requested insistently } \\
\text { to another person. }\end{array}$ \\
\hline Towards others & Example: "Stupid car!" & $\begin{array}{l}\text { Example: "Great! I am going to } \\
\text { be late because of you!" }\end{array}$ & Example: "Well! Can you call a cab then?" \\
\hline $\begin{array}{l}\text { Intra- } \\
\text { aggression }(I A)\end{array}$ & $\begin{array}{l}\text { I' - The frustrating obstacle is presented as not } \\
\text { frustrating or even beneficial; on the other } \\
\text { hand, the subject emphasizes his/her } \\
\text { embarrassment to be involved in causing } \\
\text { frustration to someone else. }\end{array}$ & $\begin{array}{l}\text { I - Blame and hostility are directed } \\
\text { towards the person himself/herself. }\end{array}$ & $\begin{array}{l}\text { The subject offers a repair to fix the } \\
\text { problem because of a sense of guilt. }\end{array}$ \\
\hline $\begin{array}{l}\text { Towards } \\
\text { themselves }\end{array}$ & $\begin{array}{l}\text { Example: "No. It's fine. I didn't want to get that } \\
\text { train anyway" }\end{array}$ & Example: "Oh no, it was my fault!" & $\begin{array}{l}\text { Example: "It's OK. I'll pay for another } \\
\text { thicket". }\end{array}$ \\
\hline $\begin{array}{l}\text { Im-magrassion } \\
\text { (MA) }\end{array}$ & $\begin{array}{l}\mathrm{M}^{\prime} \text { - Obstacle in the frustrating situation is } \\
\text { minimized, almost to the point of denying its } \\
\text { existence }\end{array}$ & $\begin{array}{l}\text { M - Blame for the situation is avoided } \\
\text { because the situation is seen as } \\
\text { unavoidable; the person who causes } \\
\text { frustration is absolved. }\end{array}$ & $\begin{array}{l}\text { M - The subject expresses the hope that } \\
\text { the time or circumstances lead to the } \\
\text { solution of the problem. Patience and } \\
\text { optimism are the main characteristics. }\end{array}$ \\
\hline $\begin{array}{l}\text { Neutralized/no } \\
\text { aggression }\end{array}$ & Example: "No problem, at all" & $\begin{array}{l}\text { Example: "Don't worry, it's not your } \\
\text { fault that the car was broken" }\end{array}$ & $\begin{array}{l}\text { Example: "Never mind. There'll be } \\
\text { another one soon" }\end{array}$ \\
\hline
\end{tabular}


Initially, we analyzed the frequencies of each category of variables (frequency, intensity). We used descriptive statistics expressed as means, SD and percentages to describe the basic features of our sample.

Variables used in the present study are assumed to be continuous (i.e., the total- and sub- scores of SAFA or PSF dimension' scores) or categorical (i.e., frequency of migraine attacks and intensity of pain). So non parametric correlations coefficients (Spearman coefficients) were calculated when continue-categorical combination of variables were involved. In order to use a correction for the number of tests, the Benjamini and Hochberg method [26] was applied.

To assess whether there was a relationship between the anxiety and the anger management style in our subjects, we performed a series of correlation analyses between all PFS indexes and SAFA-A subscales. In this case, since only continuous variables are involved, Pearson correlation coefficients with Bonferroni's corrections for multiple comparisons were calculated.

A series of one-way ANOVAs were carried out to further explore differences of the anger management style and anxiety as function of the different levels of headache frequency and intensity. We compared every PFS dimensions and SAFA-A indexes between the different groups of patients. Bonferroni's test was used for the post hoc analysis.

The level of statistical significance was set at $\mathrm{P}<0.05$.

\section{Results}

\section{Headache characteristics}

The frequency distribution indicated that most patients could be included in the LF group (37.1\%). Fourteen patients (22.6\%) suffered from high frequency attacks, while thirteen (21\%) complained a chronic migraine. Patients with an intermediate attack frequency were the fewest (19.3\%).

Most patients described pain as severe (41.9\%); pain intensity was moderate in $30.7 \%$ and mild in $27.4 \%$ of migraineurs. Clinical characteristics of our headache patients are summarized in Table 2.

\section{Frequency of attacks, intensity of pain and anger management style}

Of the nine anger management dimensions, only the IA/ OD index was positively correlated with the frequency of attack (Spearman correlation $r=0.328, p=0.041$ ) and with the pain intensity (Spearman correlation $r=0.413$, $\mathrm{p}=0.010$ ). Briefly, the higher the frequency of attacks and the intensity of pain the higher the tendency to direct the anger toward oneself in the attempt to dominate the problem. To further explore these relationships a series of ANOVA were conducted. ANOVA showed no difference in the main dimensions of anger direction
Table 2 Clinical characteristics of migraine patients

\begin{tabular}{ll}
\hline & $\mathbf{N}=\mathbf{6 2}$ \\
\hline Pain intensity & $17(27.4 \%)$ \\
Moderate & $19(30.7 \%)$ \\
Severe & $26(41.9 \%)$ \\
Frequency & \\
Low & $23(37.1 \%)$ \\
Intermediate & $12(19.3 \%)$ \\
High & $14(22.6 \%)$ \\
Chronic & $13(21.0 \%)$ \\
Associated symptoms & \\
Nausea & $32(51.6 \%)$ \\
Vomiting & $21(33.9 \%)$ \\
Phonophobia & $45(72.6 \%)$ \\
Photophobia & $40(64.5 \%)$ \\
Mean attack duration & \\
$\leq 2$ h & $35(56.4 \%)$ \\
$>2$ h & $27(43.6 \%)$ \\
Headache onset & \\
1 year & $25(40.3 \%)$ \\
$\leq 3$ years & $24(38.7 \%)$ \\
\hline
\end{tabular}

(E, I and M) and anger type (OD, ED, NP) among the attack frequency-based groups (LF, IF, HF, and CM) (Table 3). When all dimensions were compared, our data showed a significant effect of group in PFS IA/OD dimension (failure to express anger outwardly and tendency to take the blame to be involved in causing frustration to someone else) $(\mathrm{F}(3,58)=3.68 ; \mathrm{p}=0.017)$. Bonferroni's post hoc test revealed a difference between the LF and HF groups $(\mathrm{p}=0.014)$, with the higher score for the HF group. No statistical difference was found between CM and LF patients $(\mathrm{p}=0.288)$, and between IF and HF migraineurs $(\mathrm{p}=0.568)$ (Table 3$)$.

When pain severity was examined, no significant effect of pain intensity-based groups (MP, MoP, and SP) for the main dimensions of anger direction $(\mathrm{E}, \mathrm{I}$ and $\mathrm{M}$ ) and anger type (OD, ED, NP) was found. However, a significant difference was found for the IA/OD dimension. $(F(2,59)=6.78 ; p=0.002)$. SP patients showed a higher IA/OD value than MP $(\mathrm{p}=0.008)$ and $\mathrm{MoP}(\mathrm{p}=0.011)$ patients (Table 4).

In conclusion, we found a relationship between IA/ OD dimensions and both attack intensity and frequency. Children with a high attack frequency and those who complained the highest intensity showed the tendency to inhibit anger expression. In particular, they experienced the frustrating obstacle as not 
Table 3 PFS and SAFA-A scores (mean \pm standard deviation) and ANOVA among frequency based groups

\begin{tabular}{|c|c|c|c|c|c|c|}
\hline PFS dimensions & Low frequency & Intermediate frequency & High frequency & Chronic migraine & $F$ value & $\mathbf{P}$ \\
\hline $\mathrm{E}$ & $11.3 \pm 4.7$ & $13.4 \pm 4.1$ & $11.7 \pm 5.1$ & $10.9 \pm 3.7$ & 0.674 & 0.572 \\
\hline | & $5.8 \pm 2.6$ & $4.5 \pm 2.0$ & $5.9 \pm 2.6$ & $6.7 \pm 2.6$ & 1.524 & 0.218 \\
\hline M & $6.8 \pm 3.3$ & $6.0 \pm 3.2$ & $6.2 \pm 3.9$ & $6.4 \pm 2.5$ & 0.158 & 0.924 \\
\hline OD & $4.8 \pm 2.2$ & $4.9 \pm 1.9$ & $5.6 \pm 2.5$ & $4.8 \pm 1.9$ & 0.510 & 0.677 \\
\hline ED & $13.1 \pm 2.9$ & $12.5 \pm 3.7$ & $12.9 \pm 3.5$ & $12.9 \pm 2.9$ & 0.072 & 0.975 \\
\hline NP & $5.9 \pm 3.1$ & $6.6 \pm 3.7$ & $5.3 \pm 1.9$ & $6.3 \pm 3.0$ & 0.432 & 0.731 \\
\hline EA/OD & $3.1 \pm 1.9$ & $2.4 \pm 1.7$ & $2.8 \pm 1.9$ & $2.1 \pm 1.7$ & 0.831 & 0.482 \\
\hline EA/ED & $6.2 \pm 3.7$ & $7.8 \pm 3.0$ & $6.8 \pm 4.3$ & $6.6 \pm 3.4$ & 0.533 & 0.654 \\
\hline EA/NP & $2.1 \pm 1.6$ & $3.0 \pm 2.6$ & $2.7 \pm 3.3$ & $2.3 \pm 1.6$ & 0.505 & 0.680 \\
\hline IA/OD & $0.3 \pm 0.4$ & $0.5 \pm 0.6$ & $1.0 \pm 1.1$ & $0.8 \pm 0.8$ & 3.679 & $0.017^{*}$ \\
\hline IA/ED & $3.9 \pm 1.8$ & $2.5 \pm 0.8$ & $3.3 \pm 2.4$ & $3.7 \pm 1.7$ & 1.623 & 0.194 \\
\hline IA/NP & $1.6 \pm 1.6$ & $1.5 \pm 1.5$ & $1.6 \pm 1.6$ & $2.2 \pm 1.7$ & 0.514 & 0.675 \\
\hline MA/OD & $1.7 \pm 1.2$ & $1.9 \pm 1.8$ & $2.5 \pm 2.9$ & $2.1 \pm 1.5$ & 0.562 & 0.642 \\
\hline MA/ED & $2.9 \pm 2.1$ & $2.1 \pm 1.5$ & $3.5 \pm 3.8$ & $2.6 \pm 1.6$ & 0.712 & 0.548 \\
\hline MA/NP & $2.2 \pm 1.6$ & $2.0 \pm 1.4$ & $2.2 \pm 1.8$ & $2.8 \pm 0.9$ & 0.220 & 0.882 \\
\hline SAFA-A & Low frequency & Intermediate frequency & High frequency & Chronic migraine & $F$ value & $\mathbf{P}$ \\
\hline SAFA-A Ge (Generalized anxiety) & $10.5 \pm 4.9$ & $10.9 \pm 5.5$ & $9.4 \pm 4.9$ & $8.8 \pm 4.3$ & 0.527 & 0.666 \\
\hline SAFA-A So (Social anxiety) & $8.1 \pm 3.4$ & $8.5 \pm 3.1$ & $6.0 \pm 3.4$ & $8.0 \pm 4.3$ & 1.398 & 0.253 \\
\hline SAFA-A Se (Separation anxiety) & $9.4 \pm 5.0$ & $6.7 \pm 5.4$ & $7.6 \pm 4.1$ & $3.3 \pm 3.5$ & 5.229 & $0.003^{*}$ \\
\hline SAFA-A Sc (School anxiety) & $10.3 \pm 4.7$ & $9.3 \pm 5.9$ & $9.0 \pm 4.3$ & $8.3 \pm 4.7$ & 0.553 & 0.648 \\
\hline SAFA-A Tot (Total anxiety) & $38.2 \pm 14.0$ & $35.4 \pm 17.4$ & $32.0 \pm 15.4$ & $28.4 \pm 12.2$ & 1.412 & 0.248 \\
\hline
\end{tabular}

For the meaning of the PFS dimensions, see Table 1.

*P $\leq 0.05$.

frustrating or considered themselves responsible of the problem.

\section{Frequency of attacks, intensity of pain and anxiety}

Attack frequency, but not the intensity, showed a significant effect on anxiety symptoms. In particular, a negative and significant correlation emerged between Separation Anxiety (SAFA-ASE) and the frequency of attacks (Spearman correlation $\mathrm{r}=-0.409, \mathrm{p}=0.006$ ). When all subscales were compared by ANOVA, it was the "Separation anxiety" subscale score to show a significant intergroup difference $(\mathrm{F}(3,58)=5.22$; $\mathrm{p}=0.003$ ) (Table 3). LF group had higher "Separation anxiety" scores than CM patients $(\mathrm{p}=0.001)$. Pain intensity did not show any significant effect on SAFA-A subscales (Table 4).

Our data showed a relationship between the separation anxiety symptoms and the frequency of migraine attacks. In particular, children with a lower attack frequency had higher anxiety scores.

\section{Relationship between anger management style and anxiety}

Furthermore in our patient's anger management/expression style showed a relationship with anxiety symptoms.
In particular, the tendency to express and emphasize the presence of the frustrating obstacle (EA/OD) could increase anxiety level. Analyzing all PFS dimensions, we found a significant and positive correlation between EA/ OD scores (the presence of the frustrating obstacle is insistently emphasized) and the "Separation anxiety" $(\mathrm{r}=0.402 ; \mathrm{p}=0.008)$ subscales and with "Total anxiety" $(\mathrm{r}=0.345 ; \mathrm{p}=0.033)$ scales.

\section{Discussion}

This is the first study to analyze the possible correlation between anger management style (both direction and type), anxiety and headache features in a selected population of children/adolescents with migraine. The main results of the present study are:

(1)there is a relationship in terms of correlations and of mean differences between both attack frequency and intensity and failure to express the anger feelings outwardly,

(2) unlike what we expected, children with a low frequency of attacks have higher "Separation anxiety",

(3)there are correlations between the anger expression/ management style and anxiety disorders. 
Table 4 PFS and SAFA-A scores (mean \pm standard deviation) and ANOVA among pain intensity based groups

\begin{tabular}{|c|c|c|c|c|c|}
\hline PFS dimensions & Low frequency & Intermediate frequency & High frequency & $F$ value & $\mathbf{P}$ \\
\hline E & $12.4 \pm 4.3$ & $11.1 \pm 4.0$ & $11.7 \pm 4.9$ & 0.375 & 0.689 \\
\hline । & $5.2 \pm 2.5$ & $5.7 \pm 2.5$ & $6.2 \pm 2.6$ & 0.788 & 0.460 \\
\hline M & $6.3 \pm 3.1$ & $7.0 \pm 3.4$ & $6.0 \pm 3.2$ & 0.535 & 0.589 \\
\hline OD & $5.2 \pm 1.8$ & $4.4 \pm 2.2$ & $5.3 \pm 2.3$ & 0.920 & 0.404 \\
\hline ED & $13.4 \pm 2.1$ & $13.3 \pm 2.9$ & $12.2 \pm 3.8$ & 0.979 & 0.382 \\
\hline NP & $5.2 \pm 2.6$ & $5.9 \pm 2.3$ & $6.5 \pm 3.4$ & 1.088 & 0.344 \\
\hline EA/OD & $3.1 \pm 1.7$ & $2.4 \pm 1.8$ & $2.6 \pm 1.9$ & 0.693 & 0.504 \\
\hline EA/ED & $6.8 \pm 3.5$ & $6.6 \pm 2.9$ & $6.7 \pm 4.3$ & 0.007 & 0.993 \\
\hline $\mathrm{EA} / \mathrm{NP}$ & $2.5 \pm 2.3$ & $2.6 \pm 2.9$ & $2.4 \pm 1.6$ & 0.490 & 0.952 \\
\hline IA/OD & $0.3 \pm 0.5$ & $0.3 \pm 0.5$ & $1.0 \pm 0.9$ & 6.780 & $0.002^{*}$ \\
\hline IA/ED & $3.8 \pm 2.1$ & $3.9 \pm 1.7$ & $3.1 \pm 1.8$ & 1.279 & 0.286 \\
\hline IA/NP & $1.1 \pm 1.2$ & $1.5 \pm 1.6$ & $2.2 \pm 1.7$ & 2.624 & 0.081 \\
\hline MA/OD & $1.9 \pm 1.4$ & $1.9 \pm 1.7$ & $2.0 \pm 2.3$ & 0.420 & 0.959 \\
\hline MA/ED & $2.9 \pm 2.4$ & $3.3 \pm 3.0$ & $2.5 \pm 1.9$ & 0.686 & 0.508 \\
\hline MA/NP & $1.5 \pm 0.8$ & $2.4 \pm 1.3$ & $2.2 \pm 1.9$ & 1.418 & 0.250 \\
\hline SAFA-A & Low frequency & Intermediate frequency & High frequency & $F$ value & $\mathbf{P}$ \\
\hline SAFA-A Ge (Generalized anxiety) & $8.8 \pm 4.7$ & $11.1 \pm 4.9$ & $9.8 \pm 4.9$ & 1.086 & 0.344 \\
\hline SAFA-A So (Social anxiety) & $7.9 \pm 3.4$ & $6.8 \pm 3.2$ & $8.2 \pm 4.1$ & 0.808 & 0.451 \\
\hline SAFA-A Se (Separation anxiety) & $7.8 \pm 5.4$ & $7.2 \pm 4.6$ & $6.9 \pm 4.9$ & 0.167 & 0.847 \\
\hline SAFA-A Sc (School anxiety) & $9.0 \pm 4.7$ & $10.6 \pm 3.8$ & $8.8 \pm 5.5$ & 0.803 & 0.453 \\
\hline SAFA-A Tot (Total anxiety) & $33.6 \pm 14.9$ & $35.7 \pm 13.9$ & $33.7 \pm 15.8$ & 0.121 & 0.886 \\
\hline
\end{tabular}

*P $\leq 0.05$.

For the meaning of the PFS dimensions, see Table 1.

Headache severity and anger management

Among our patients, children with higher attack frequency and intensity had the tendency to inhibit anger expression, that is to appear as if they considered the frustrating obstacle as not frustrating or to blame themselves (IA/OD index) to cause frustration to someone else.

That in our study only the HF patients, but not the CM migraineurs, were significantly different in the IA/OD index from the LF group is difficult to explain. We can hypothesize that, as suggested by several studies [27,28], the pathophysiological mechanisms of pain in chronic migraineurs are different from those in patients with episodic migraine. This can make it difficult to compare CM subjects with patients with episodic migraine. A further hypothesis is that the relationship between headache severity and anger management is not linear, but it increases in the passage between LF and HF and then it reaches a plateau. As a consequence, no more differences can be found between HF and CM patients.

Very few studies analyzed the role of anger in the headache frequency and intensity [13,15-17] and only one study dealt with children [20]. In adult patients, no significant correlation was found between the anger management style and both headache frequency and intensity $[13,16,17]$. In children, Kristjándóttir found that young headache sufferers with higher attack frequency were those who showed also higher anger levels [20]. The disagreement between these previous results and our data, showing worse headache frequency in patients with lower anger scores, can be due to 3 main elements: 1) Kristjándóttir's study was a part of a large investigation of self-report pain in school children and did not focus on patients suffering from migraine; 2) headache diagnosis was performed by a self report questionnaire and was not based on the ICHD-II criteria [21]; 3) the author did not use a standardized test to assess the main components of anger.

\section{Headache and anxiety}

In the present study, Separation anxiety subscale showed the highest scores in the migraineurs with a low attack frequency. Separation anxiety disorder (SAD) is an anxiety disorder of middle childhood characterized by an excessive worry about separation from another person who represents safety for the affected child, typically a parent $[29,30]$. Somatic symptoms such as headache, nausea and more often abdominal pain are common features of SAD [29,31]. They often occur in the context of separation situation, reflecting either an avoidance strategy or genuine physical distress. Children and 
adolescents who have insecure models of attachment may display exaggerated nonverbal affective signals such as anger, fear, somatic complaints or desire for comfort, thereby eliciting more predictable responses from parents [32,33]. Previous research has shown that these children report high pain intensity and disability [34,35]. These previous results seem in disagreement with our present findings showing that the lower the attack frequency was, the worse the SAD the child could experience. This can be explained by the fact that previous studies did not deal with migraine [31,34-36]. Insecure attachment represents a predictor for higher disability in adult migraineurs [37,38]. To our knowledge, there are not studies investigating the possible relationship between attachment and headache in pediatric age. Although we did not investigate the attachment style with specific psychological tools, our results suggest that in children attachment oriented to the proximity may reduce headache severity.

\section{Relationship between anxiety and anger management}

While the relationship between anger expression and depression has been repeatedly investigated in headache [12,14-17] and in chronic pain [39], possible correlations between anger and anxiety have been rarely explored and all studies referred to adulthood $[12,16]$. The current study, performed on a pediatric headache population, confirmed the relationship between anger and anxiety described in adult populations [16]. In our patients, anger directed outwards (EA/OD index) was associated with separation and school anxiety. Anger is a negative affect and anxiety may depend on overt expression of anger, which could make the individual less lovable. This can be explained, considering that perceived consequences of anger may include fear of being "unacceptable" by parents who usually are the most important attachment figures in pediatric age [40].

\section{Limitations of the study}

The present study has some limitations that have to be underlined. 1) The explored relationships have a correlational character. Further prospective longitudinal studies need to be conducted in order to ascertain if there exist a causal relationship between the variables involved. 2) Our results were issued from children who were clinically referred to our third-level centre for the treatment of primary headache. This may represent a selection bias with regard to the whole population of patients suffering from migraine without aura. 3) The study was a pilot study and it did not include a group of healthy controls. Future studies involving a larger sample size and the presence of a control group are required to draw definitive conclusions. 4) Limitations of the psychological tools have also to be addressed. The SAFA-A test, used to investigate anxiety, has a fundamental selfreport nature. Concerning the PFS, the validity of the aggressiveness measures might be hampered by social desirability and self-presentational concerns about a socially unacceptable behaviour as aggression.

\section{Conclusions}

This is the first study to analyze the relationship between anger, anxiety and headache in a paediatric population. We found that children suffering from severe migraine tend to inhibit their angry feelings. Moreover, anger is associated with anxiety symptoms (separation anxiety), which, on their turn, are typical of migraineurs with a low attack frequency. In conclusion, our results suggest that children with worse migraine symptoms (intensity and frequency of the attacks) are those who less often express their anger. On the contrary, children with low migraine attack frequency express their anger and suffer from separation anxiety.

Future studies will have to test whether these psychological features can be important in migraine therapeutical management.

Competing interests

The authors declare that they have no competing interests.

\section{Authors' contributions}

ST and MV conceived and supervised the project, drafted the manuscript and were the main authors. ST, CDR and SG were responsible for data collection. CD and FP were involved in data analysis and interpretation and assisted in preparation of the manuscript. MC, AC, FG, VG and FG critically reviewed and revised this manuscript for important intellectual inputs. All authors read and approved the manuscript.

\section{Author details}

${ }^{1}$ Division of Neurology, Headache Centre, Ospedale Pediatrico Bambino Gesú, IRCCS, Rome, Italy. ${ }^{2}$ Unit of Clinical Psychology Ospedale Pediatrico Bambino Gesù, IRCCS, Rome, Italy. ${ }^{3}$ Faculty of Medicine and Psychology, "La Sapienza" University of Rome, Rome, Italy. ${ }^{4}$ Headache Science Centre of the IRCCS "National Institute of Neurology C. Mondino" Foundation, Pavia, Italy. ${ }^{5}$ Center for Sensory-Motor Interaction, Aalborg University, Aalborg, Denmark.

Received: 15 November 2012 Accepted: 30 April 2013

Published: 7 May 2013

\section{References}

1. Nicholson RA, Houle TT, Rhudy JL, Norton PJ (2007) Psychological risk factors in headache. Headache 47(3):413-426, review

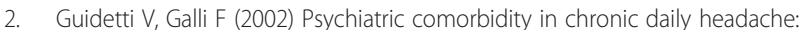
pathophysiology, etiology, and diagnosis. Curr Pain Headache Rep 6(6):492-497, review

3. Antonaci F, Nappi G, Galli F, Manzoni GC, Calabresi P, Costa A (2011) Migraine and psychiatric comorbidity: a review of clinical findings. J Headache Pain 12(2):115-125, review

4. Powers SW, Gilman DK, Hershey AD (2006) Headache and psychological functioning in children and adolescents. Headache 46(9):1404-1415, review

5. Fernandez E, Turk DC (1995) The scope and significance of anger in the experience of chronic pain. Pain 61(2):165-175

6. Kerns RD, Rosenberg R, Jacob MC (1994) Anger expression and chronic pain. J Behav Med 17(1):57-67

7. Burns JW, Johnson BJ, Devine J, Mahoney N, Pawl R (1998) Anger management style and the prediction of treatment outcome among male and female chronic pain patients. Behav Res Ther 36(11):1051-1062 
8. Okifuji A, Turk DC, Curran SL (1999) Anger in chronic pain: investigations of anger targets and intensity. J Psychosom Res 47(1):1-12

9. Sayar K, Gulec H, Topbas M (2004) Alexithymia and anger in patients with fibromyalgia. Clin Rheumatol 23(5):441-448

10. Thomas E, Moss-Morris R, Faquhar C (2006) Coping with emotions and abuse history in women with chronic pelvic pain. J Psychosom Res 60 (1):109-112

11. Spielberger CD, Johnson EH, Russell SF, Crane RJ, Jacobs GA, Worden TI (1985) The experience and expression of anger: construction and validation of an anger expression scale. In: Chesney MA, Rosenman RH (eds) Anger and hostility in cardiovascular and behavioral disorders. Hemisphere, New York

12. Nicholson RA, Gramling SE, Ong JC, Buenaver L (2003) Differences in anger expression between individuals with and without headache after controlling for depression and anxiety. Headache 43(6):651-663

13. Perozzo P, Savi L, Castelli L, Valfrè W, Lo Giudice R, Gentile S, Raniero I, Pinessi L (2005) Anger and emotional distress in patients with migraine and tension-type headache. J Headache Pain 6(5):392-399

14. Abbate-Daga G, Fassino S, Lo Giudice R, Rainero I, Gramaglia C, Marech L, Amianto F, Gentile S, Pinessi L (2007) Anger, depression and personality dimensions in patients with migraine without aura. Psychother Psychosom 76(2):122-128

15. Materazzo F, Cathcart S, Pritchard D (2000) Anger, depression, and coping interactions in headache activity and adjustment: a controlled study. J Psychosom Res 49(1):69-75

16. Venable VL, Carlson CR, Wilson J (2001) The role of anger and depression in recurrent headache. Headache 41(1):21-30

17. Tschannen TA, Duckro PN, Margolis RB, Tomazic TJ (1992) The relationship of anger, depression, and perceived disability among headache patients. Headache 32(10):501-503

18. Odegaard G, Lindbladh E, Hovelius B (2003) Children who suffer from headaches: a narrative of insecurity in school and family. Br J Gen Pract 53 (488):210-213

19. Lanzi G, Zambrino CA, Ferrari-Ginevra O, Termine C, D'Arrigo S, Vercelli P, De Silvestri A, Guglielmino CR (2001) Personality traits in childhood and adolescent headache. Cephalalgia 21(1):53-60

20. Kristjándóttir G (1997) The relationship between pains and various discomforts in school children. Childhood 4(4):491-504

21. Headache Classification Committee of International Headache Society (2004) Classification and diagnostic criteria for headache disorders, cranial neuralgias and facial pain, 2nd edition. Cephalalgia 24(Suppl 1):1-160

22. Bihldorff JP, King SH, Parnes LR (1971) Psychological factors in headache. Headache 11:117-127

23. Rosenzweig S (1992) PFS-Picture frustration study. Lo studio della reazione alle frustrazioni Lo studio della reazione alla frustrazione. Lo studio della reazione alle frustrazioni Organizzazioni Speciali, Firenze

24. Rosenzweig S, Ludwig DJ, Adelman S (1975) Retest reliability of the rosenzweig picture-frustration study and similar semiprojective techniques. J Pers Assess 39(1):3-12

25. Cianchetti C, Sannio Fascello G (2001) Scale psichiatriche di autosomministrazione per fanciulli e adolescenti (SAFA). Organizzazioni Speciali, Firenze

26. Benjamini Y, Hochberg Y (1995) Controlling the false discovery rate: a practical and powerful approach to multiple testing. J Roy Stat Soc Ser B 57:289-300

27. Ferraro D, Vollono C, Miliucci R, Virdis D, De Armas L, Pazzaglia C, Le Pera D, Tarantino S, Balestri M, Di Trapani G, Valeriani M (2012) Habituation to pain in "medication overuse headache": a CO2 laser-evoked potential study. Headache 52(5):792-807

28. Coppola G, Schoenen J (2012) Cortical excitability in chronic migraine. Curr Pain Headache Rep 16(1):93-100

29. American Psychiatric Association (2000) Diagnostic and statistical manual of mental disorders (4th edn-text revision). Task Force, Washington, DC

30. Ehrenreich JT, Santucci LC, Weiner CL (2008) Separation anxiety disorder in youth: phenomenology, assessment, and treatment. Psicol Conductual 16 (3):389-412

31. Walker LS, Beck J, Anderson J (2009) Functional abdominal separation anxiety: helping the child return to school. Pediatr Ann 38(5):267-271

32. Kozlowska K (2009) Attachment relatioships shape pain-signaling behavior. J Pain 10(10):1020-1028, review
33. Bowlby J (1973) Attachment and Loss, vol 2: Separation. Basic Book, New York

34. Walsh TM, McGrath PJ, Symons DK (2008) Attachment dimentions and young children's response to pain. Pain Res Manag 13(1):33-40

35. Tremblay I, Sullivan MJ (2010) Attachment and pain outcomes in adolescents: the mediating role of pain catastrophizing and anxiety. J Pain 11(2):160-171

36. Puskar KR, Sereika SM, Haller LL (2003) Anxiety, somatic complaints, and depressive symptoms in rural adolescents. J Child Adolesc Psychiatr Nurs 16(3):102-111

37. Rossi P, Di Lorenzo G, Malpezzi MG, Di Lorenzo C, Cesarino F, Faroni J, Siracusano A, Troisi A (2005) Depressive symptoms and insecure attachment as predictors of disability in a clinical population of patients with episodic and chronic migraine. Headache 45(5):561-570

38. Savi L, Buccheri R, Tambornini A, De Martino P, Albasi C, Pinessi L (2005) Attachment styles and headache. J Headache Pain 6(4):254-257

39. Burns JW, Quartana PJ, Bruehl S (2008) Anger inhibition and pain: conceptualizations, evidence and new directions. J Behav Med 31(3):259-279, review

40. Waldinger RJ, Schulz MS, Barsky AJ, Ahern DK (2006) Mapping the road from childhood trauma to adult somatization: the role of attachment. Psychosom Med 68(1):129-135

doi:10.1186/1129-2377-14-39

Cite this article as: Tarantino et al: Clinical features, anger management and anxiety: a possible correlation in migraine children. The Journal of Headache and Pain 2013 14:39.

\section{Submit your manuscript to a SpringerOpen ${ }^{\odot}$ journal and benefit from:}

- Convenient online submission

- Rigorous peer review

- Immediate publication on acceptance

- Open access: articles freely available online

High visibility within the field

- Retaining the copyright to your article

Submit your next manuscript at $\gg$ springeropen.com 